\title{
LA COMPLEMENTARIEDAD LITORAL-INTERIOR EN EL MARCO DE LA RENOVACIÓN DE DESTINOS TURÍSTICOS CONSOLIDADOS: EL EXCURSIONISMO ORGANIZADO, COMO ELEMENTO DE RELACIÓN ${ }^{1}$
}

\author{
Carlos Baños Castiñeira \\ Elisa Rico Cánovas \\ Universidad de Alicante
}

\section{RESUMEN}

La complementariedad entre el litoral y el interior es una de las líneas de actuación habitualmente incluidas entre las estrategias orientadas a la renovación de destinos turísticos consolidados del litoral. Las excursiones turísticas con base en los destinos litorales constituyen uno de los mecanismos que han catalizado esas relaciones de complementariedad. El artículo se centra en el análisis del fenómeno de las excursiones turísticas en la provincia de Alicante, particularmente en aquellas con origen en el destino Benidorm. Se identifican los factores que determinan la intensidad de uso turístico de los recursos patrimoniales y las potenciales vías de profundización en el fenómeno excursionista.

Palabras clave: patrimonio cultural; destinos litorales consolidados; Benidorm; excursionismo; diversificación; complementariedad territorial.

Recibido: 3 de agosto de 2015

Devuelto para su revisión: 13 de octubre de 2015

Aceptado: 30 de noviembre de 2015

Instituto Universitario de Investigaciones Turísticas. Universidad de Alicante. Apartado 99. 03080 ALICANTE (España). E-mail: carlos.banos@ua.es, elisa.rico@ua.es

1 Este trabajo se enmarca en el proyecto Metodología, criterios y aplicaciones para la configuración de destinos o clusters en áreas turísticas consolidadas: innovación, complementariedad y competitividad territorial, financiado por el Plan Nacional de Investigación Científica y Desarrollo Tecnológico, del Ministerio de Economía y Competitividad, con referencia CSO2011-26396, vigente desde el 1/1/2012 al 31/12/2014. 


\title{
The coastal-interior complementarity within the renewal of consolidated tourist destinations: organized excursionism as element of relationship
}

\begin{abstract}
The complementarity between the coast and inner land is one of the proceeding lines usually included among the strategies oriented to the renewal of coastal consolidated tourist destinations. Tourist day trips, that the starting point is in coastal destinations, are one of the mechanisms that have catalyzed these complementarity relationships. The article focuses in the analysis of tourist day trips in the province of Alicante, particularly those originating in Benidorm. It is identified the factors that determine the tourist use intensity of heritage resources and potential ways for deepening on hiker phenomenon.
\end{abstract}

Keywords: cultural heritage; coastal consolidated tourist destinations; Benidorm; day trips; diversification; territorial complementarity.

\section{INTRODUCCIÓN}

La consolidación del turismo en distintas regiones del Mediterráneo, basado en la explotación de los recursos ecológicos y ambientales del clima y el litoral, ha supuesto una profunda reorganización de las estructuras territoriales de estos espacios. Se ha producido la concentración de las inversiones en una estrecha franja del litoral que polariza las iniciativas y el empleo (Vera, López, Marchena y Anton, 2011) lo que ha generado la colmatación urbano-turística de numerosos tramos del litoral y la configuración de conurbaciones que ocupan longitudinalmente los primeros sectores de costa. En el caso de destinos de varios países mediterráneos como Creta (Andriotis, 2000, 2006), Croacia (Jordan, 2000), la península de Bodrum en Turquía (Idikut y Edelman, 2003).

El proceso es similar, incluso más acusado, en el litoral mediterráneo español donde el turismo ha venido a acelerar el proceso de transferencia de activos desde los espacios de interior al litoral, transformaciones iniciadas en la primera mitad del siglo XX con la crisis de la agricultura tradicional, lo que ha generado un intenso contraste social, económico y demográfico entre ambas áreas, manifestado en la despoblación de las comarcas de interior y la consecuente incapacidad de esas poblaciones para mantener un sistema de servicios y equipamientos diverso lo que vendría a incrementar, en definitiva, las diferencias entre regiones desarrolladas y regiones subdesarrolladas (Bramwell, 2004).

En la escala regional el fenómeno es observable incluso en aquellas regiones con una gran diversidad de recursos y potentes productos no vinculados al litoral (turismo urbano, montaña). Es el caso de Cataluña, cuyo mapa turístico presenta una notable asimetría, con fuerte concentración de actividades y oferta en el litoral con una clara hegemonía del sol y playa (López Palomeque, 2009) -esquema que se confirma en las escalas subregionales como la Costa Brava, donde Donaire, Fraguell y Mundet (1998) citan como una de las características más notables la ausencia de traspaís- o Andalucía donde un $70 \%$ de la oferta reglada se concentra en el litoral (Fernández y Mendoza, 2007). 
La región valenciana y de manera particular la provincia de Alicante, participa de las características de estos modelos duales en los que el turismo se ha convertido en una actividad clave para entender su realidad socioeconómica, demográfica y, en definitiva, territorial. En el proceso de implantación del turismo en el litoral las áreas de interior, como hinterland, han jugado en la mayor parte de los casos un papel secundario, con una funcionalidad limitada y secundaria:

- Ha quedado relegado a funciones de suministro de mano de obra y recursos naturales (por ejemplo agua).

- En otros casos, el turismo desborda tanto territorial como conceptualmente la franja litoral y pasa a ocupar espacios de ese traspaís en forma de urbanizaciones vacacionales o segundas residencias, es decir, el papel de ese entorno territorial no pasa de ser el de una de una reserva de suelo para los procesos expansivos de un litoral ya colmatado que traslada al interior fórmulas turísticas masivas y reproduce los consabidos mecanismos de creación de espacios semiurbanos con el único objeto de generar plusvalías inmobiliarias.

- En una dinámica más integrada en la producción de ocio, esas zonas de interior próximas a los focos turísticos litorales pueden generar la aparición de pequeños flujos de visitantes casi espontáneos motivados por el aprovechamiento de los recursos naturales y culturales existentes.

- En última instancia, obviamente los espacios de interior pueden generar sus propias dinámicas turísticas, al margen de los flujos del litoral (Vera, López, Marchena y Anton, 2011). Sin embargo, en el caso de la provincia de Alicante esas dinámicas lejos de conseguir consolidarse, muestran una importante debilidad en la creación de producto (Díez, 2012).

No obstante, la asociación del turismo español con un modelo turístico litoral se ve ampliamente matizada mediante el análisis de la diversidad geográfica del territorio español, que comprende un rico patrimonio natural y cultural, que justifica la existencia de otros tipos de turismo que avalan el eslogan «mucho más que playa» (López Palomeque y Vera Rebollo, 2001).

La débil articulación entre litoral e interior se ha traducido en una serie de repercusiones negativas tanto territoriales como sectoriales que lastran la optimización de emprendimientos turísticos, sin embargo la planificación del espacio turístico desde la escala comarcal plantea vías para revertir esta situación (Fernández, 2004). Desde el último decenio del siglo $\mathrm{XX}$ se ha venido señalando la complementariedad litoral-interior, la búsqueda de fórmulas de integración entre los espacios interiores adyacentes y los destinos turísticos litorales, como una de las posibles estrategias de renovación y/o reestructuración de los destinos turísticos de sol y playa maduros (López Palomeque y Vera Rebollo, 2001; Vera, López, Marchena y Anton, 2011; Anton, 2004) de manera que pudieran incorporarse los recursos de esos espacios de interior, -patrimonio natural y cultural, paisaje- como ofertas recreativas complementarias a los productos del litoral. Se trata de una estrategia que incide en la adaptación de los destinos litorales consolidados ante los escenarios turísticos que delimitan las nuevas tendencias de la demanda, asociadas al cambio cultural 
del postmodernismo, que tienen su réplica en la teórica evolución de la oferta hacia el postfordismo (Vera y Baños, 2010). Entre otras líneas, esta estrategia incorpora acciones de puesta en valor de recursos patrimoniales y naturales para su aprovechamiento turística y recreativo, la valorización de nuevos recursos o la incorporación del destino al espacio supralocal (Anton, 2004). Por otra parte, se trata de una línea de actuación que obliga a una reflexión en torno a nuevas fórmulas de gobernanza y herramientas de gestión ya que las escalas operativas superan el tradicional marco local siendo las escalas subregionales las más adecuadas. Asimismo, los objetivos deberían ir más allá de la adecuación de los destinos de sol y playa a las nuevas situaciones derivadas de esos escenarios e incorporar orientaciones de reequilibrio territorial de manera que el turismo actúe como un verdadero factor de mejora social, eliminando los mecanismos de gobierno «desde la distancia» (Cànoves, Villarino y Herrera, 2006).

Sin embargo, es esta una vía de trabajo menos desarrollada y con menor recorrido hasta el momento que otras opciones de diversificación y modernización de áreas turísticas maduras. Los principales instrumentos de la política turística estatal, Planes Marco de Competitividad I y II, PICTE, Plan 2020², Plan Nacional e Integral del Turismo 2012-2015 no recogen explícitamente una estrategia de complementariedad territorial turística entre entornos territoriales diversos a pesar de señalar los elementos que justificarían tales orientaciones (concentración en litoral de oferta y demanda, valoración de recursos naturales y patrimoniales por parte de las nuevas demandas turísticas, necesidad de diversificación de los destinos maduros, apuesta por el reequilibrio territorial), pues las actuaciones en materia territorial turística centran la atención sobre los destinos a escala local.

La intensa asimilación de municipio y destino en el turismo litoral, queda reflejada en la orientación dada a los diferentes planes apoyados en los distintos instrumentos señalados (Planes de Excelencia, Dinamización, Competitividad o de Dinamización del Producto Turístico). En el caso de los aprobados para la Comunidad de los 18 planes aprobados en ámbito regional 10 corresponden a destinos litorales consolidados y solo en el caso del Plan de Competitividad Turística Benicarló-Peñíscola, orientado a la potenciación de la Estación Náutica, se supera el estricto marco de la escala local.

En el caso valenciano, la perspectiva se modifica, al menos sobre el papel, en las propuestas emanadas de la política regional. El Plan de Espacios Turísticos de la Comunidad Valenciana (PETCV), instrumento de política turística orientado a recomponer el sistema turístico valenciano desde una óptica territorial, recoge la necesidad de plantear esa visión subregional en la planificación turística y las posibilidades del turismo como factor de reequilibrio territorial incorporando, entre otras, directrices y actuaciones que fomenten la complementariedad entre áreas y destinos turísticos y la consiguiente sinergia territorial. Para el área de la comarca de la Marina Baixa, ámbito territorial sobre el que se centra este trabajo, el PECTV señala que el comportamiento de la oferta y la demanda turística en Benidorm difiere notablemente del resto de la comarca y de la provincia, debido al

2 No obstante, el Plan del Turismo Español Horizonte 2020 plantea con claridad la superación de la escala municipal como marco territorial de la planificación turística, si bien no directamente en las acciones de renovación de destinos, e introduce la escala comarcal como una de las vías de trabajo orientadas a promover un nuevo reequilibrio territorial. 
dinamismo de su oferta y su integración en el mercado turístico, y se incide en que las posibilidades de complementariedad turística entre los municipios que integran este espacio son numerosas. El litoral concentra la actividad turística y residencial pero se aprecia una tendencia creciente hacia la difusión en los municipios de segunda línea, integrados en un traspaís montañoso de indudable valor ambiental y paisajístico que, a su vez, posibilita el desarrollo de modalidades turísticas específicas (turismo rural, naturaleza, activo, etc.), además de su función tradicional como destinos excursionistas.

En efecto, una de las manifestaciones comunes de las relaciones entre el turismo del litoral y las áreas del traspaís se concreta en los flujos de excursionistas que se generan desde los focos turísticos litorales a las áreas próximas. Se trata, como se ha señalado anteriormente, de flujos de carácter espontáneo mediante excursiones individuales asociadas comúnmente al alquiler de vehículos o colectivos a través de excursiones organizadas por agencias receptivas locales, que incorporan atractivos normalmente ligados a recursos naturales, culturales, paisajísticos e incluso al tipismo de la zona.

\section{OBJETIVOS Y METODOLOGÍA}

Este trabajo se enmarca en el indicado proyecto Metodología, criterios y aplicaciones para la configuración de destinos o clusters en áreas turísticas consolidadas: innovación, complementariedad y competitividad territorial, centrado en el análisis y propuestas de optimización del sistema de relaciones entre territorios y recursos cuya complementariedad permitiría abrir nuevas perspectivas turísticas y funcionales. En ese contexto, el objetivo principal del presente artículo se centra en el análisis del fenómeno de las excursiones turísticas en la provincia de Alicante, particularmente en aquellas irradiadas desde el gran destino turístico y de ocio valenciano, Benidorm, en la identificación de las causas que determinan la intensidad de uso turístico de los recursos patrimoniales en el fenómeno excursionista de este destino.

En definitiva, desde el enfoque de la dimensión territorial de las actividades turísticorecreativas se trata de realizar una aportación en torno al potencial que de estas actividades recreativas puedan de derivarse como vía de complementariedad entre el litoral y el interior.

A través del estudio de los catálogos de las agencias locales organizadoras de las excursiones y de los canales de promoción de los organismos públicos locales, desde el enfoque de la oferta el trabajo se centra en los siguientes aspectos:

- Análisis de las principales rutas de excursionismo organizado con base en Benidorm.

- Sistematización de los destinos y recursos más relevantes puestos en valor e integrados en las rutas excursionistas.

- Identificación de los factores y características que permiten integrar a los lugares en la red de excursiones.

A partir de ese análisis se ponen de manifiesto los efectos positivos sobre el modelo turístico que hasta el momento han podido derivarse del desarrollo de las excursiones, las amenazas y los riesgos que se producen como resultado de las altas tasas de frecuentación 
y presión ejercidas sobre localidades y recursos en que, en la mayor parte de las ocasiones, no se han incorporado criterios de gestión y planificación de esas actividades, así como las potencialidades y las oportunidades que puedan obtenerse a corto y medio plazo como resultado de la integración de nuevos recursos en el sistema territorial-turístico mediante la articulación que permite esta red de excursiones turísticas.

En última instancia, con objeto de mostrar con mayor claridad la realidad del patrimonio cultural en este marco de trabajo, se ha centrado la atención en dos estudios de caso, de sendos destinos localizados en los municipios del Castell de Guadalest (interior) y la Vila Joiosa (litoral), situados en la comarca de la Marina Baixa, por tanto, en el ámbito de influencia territorial de la ociurbe de Benidorm. Estos dos casos, de distinta forma, han contribuido a proporcionar recursos turísticos para el fenómeno excursionista pero revelan importantes diferencias en intensidad de uso turístico de los mismos, derivadas de las características particulares de los procesos de activación patrimonial realizados. En relación con esos procesos de puesta en valor, en opinión de los autores, se plantean diferentes escenarios de futuro.

\section{LA ESTRATEGIA DE DIVERSIFICACIÓN DEL PRODUCTO TURÍSTICO: EL PATRIMONIO CULTURAL EN LOS PROCESOS DE RENOVACIÓN. UNA APROXIMACIÓN A LA COSTA BLANCA}

El patrimonio cultural posee una evidente dimensión turística que se traduce en términos de mercantilización de la cultura y viabilidad turística del patrimonio (Martín, 2014; Prats, 2011, 2006), rasgos que definen el marco de trabajo en el que se han de incluir los procesos de gestión de los recursos patrimoniales. En estos procesos el turismo ha adquirido un protagonismo social relevante ya que permite desarrollar el ocio del individuo en el contexto del postmodernismo, donde el patrimonio cultural ha ampliado el conjunto de posibilidades para desarrollar estas prácticas de ocio. Este hecho sitúa a determinados referentes patrimoniales en los circuitos de uso recreativo y turístico, para los que es imprescindible acometer procesos de valoración y activación (Prats, 2006: 79) con el objetivo de convertir los recursos patrimoniales en productos turísticos que puedan ser adquiridos por el consumidor final, aspecto que constituye todavía en la actualidad una de las grandes debilidades de la gestión turística del patrimonio (Chías, 2002) ya que la sola presencia de atractivos patrimoniales no implica la existencia de recursos turísticos, de oferta turística cultural y por tanto, de productos turísticos (Grande Ibarra, 2001; Ruiz Baudrihaye, 1997; Calle, 2002; Tresserras y Matamala, 2005). De ahí que en los procesos de activación turística del patrimonio sea prioritario partir de la claridad conceptual de estos términos que constituyen los elementos fundamentales sobre los que sustentar cualquier proceso de activación turística patrimonial (Leno, 1993).

En destinos litorales especializados en el producto de sol y playa, el uso de los recursos patrimoniales ha ido encaminado a complementar dichos espacios, utilizando habitualmente los valores localizados en el hinterland inmediato, convirtiendo la estrategia de diversificación del producto turístico en uno de los argumentos más utilizados en los procesos de renovación de los destinos mencionados. Existen diversas formas de utilizar los recursos patrimoniales en el marco de esta estrategia competitiva (Cuadro 1): la recu- 


\section{Cuadro 1}

\section{EL PATRIMONIO CULTURAL EN LA ESTRATEGIA DE DIVERSIFICACIÓN DE DESTINOS LITORALES CONSOLIDADOS}

\begin{tabular}{|c|c|c|}
\hline AUTOR & ESTRATEGIA DE DIVERSIFICACIÓN & DESTINO \\
\hline Clegg y Essex (2000) & $\begin{array}{l}\text { Desarrollo de enclaves patrimoniales (eventos históricos, personajes } \\
\text { literarios, recuperación del patrimonio histórico) }\end{array}$ & Torbay (Reino Unido) \\
\hline Callegari (2003) & $\begin{array}{l}\text { Valorización de la cultura marítima (navegación, transporte marítimo, } \\
\text { comercio histórico) }\end{array}$ & Costa ligur (Italia) \\
\hline Figini y Vici (2012) & Valorización del patrimonio cultural & Rímini (Italia) \\
\hline Theuma (2004) & Valorización del patrimonio histórico y cultural & Valetta (Malta) \\
\hline Branwell (2004) & $\begin{array}{c}\text { Desarrollo de turismos alternativos, entre ellos el cultural (interpretación, } \\
\text { museos, lugares históricos) }\end{array}$ & $\begin{array}{l}\text { Destinos de sudeste de } \\
\text { Europa }\end{array}$ \\
\hline Donaire y Mundet (2001) & Valorización del patrimonio cultural & Litoral catalán (España) \\
\hline Prat y Cánoves (2012) & Museos de la marca Dalí & $\begin{array}{l}\text { Costa Brava (Girona, } \\
\text { Cataluña) }\end{array}$ \\
\hline Anton (2004) & $\begin{array}{l}\text { Variedad de productos que se incorporan a la oferta turística tradicional } \\
\text { (golf, parques temáticos, náutica, deporte, cultura, naturaleza...) }\end{array}$ & España \\
\hline Calabuig y García, (2006) & $\begin{array}{l}\text { Valorización del patrimonio arqueológico, museos, eventos históricos, } \\
\text { servicios de interpretación del patrimonio }\end{array}$ & Tarragona (España) \\
\hline $\begin{array}{l}\text { Amer, Arrom y Picornell } \\
(2006)\end{array}$ & Propuesta de valorización del centro histórico de Palma de Mallorca & $\begin{array}{l}\text { Palma de Mallorca } \\
\text { (España) }\end{array}$ \\
\hline González Pérez (2012) & Espacios tematizados y catedrales por núcleos urbanos & Playa de Palma (España) \\
\hline Sedmark y Mihalic (2008) & $\begin{array}{l}\text { Conexión con el hinterland, búsqueda de la autenticidad a través de los } \\
\text { elementos patrimoniales }\end{array}$ & Piran (Eslovenia) \\
\hline Chávez y Pérez (2010) & $\begin{array}{l}\text { Potencialidad del patrimonio arqueológico (Cueva pintada de Gáldar, } \\
\text { Museo Arqueológico de La Gomera, Museo Arqueológico de La Laguna) }\end{array}$ & Islas Canarias (España) \\
\hline Oreja Rodríguez (2000) & Valorización del patrimonio cultural del Valle de la Orotava & Tenerife (España) \\
\hline Zoreda (2007) & $\begin{array}{l}\text { Propone el aprovechamiento del patrimonio cultural como elemento } \\
\text { distintivo, identitario y diferencial del litoral español }\end{array}$ & España \\
\hline Vera y Baños (2010) & $\begin{array}{l}\text { Diversificación como complemento al sol y playa, desarrollo de } \\
\text { actividades recreativas asociadas al golf, náutica, cultura y naturaleza }\end{array}$ & Costa Blanca (España) \\
\hline Kozak y Martín (2012) & $\begin{array}{c}\text { Creación de nuevos productos turísticos (patrimonio cultural, aventura, } \\
\text { salud, naturaleza) para mantener a los turistas platinum y fidelizar a la } \\
\text { demanda de interés }\end{array}$ & $\begin{array}{c}\text { Destinos litorales egeos y } \\
\text { mediterráneos (Turquía) }\end{array}$ \\
\hline Spilanis y Vayani (2004) & $\begin{array}{c}\text { Desarrollo de turismo cultural a partir de la valorización de elementos } \\
\text { arqueológicos, gastronomía, elementos etnográficos, patrimonio } \\
\text { industrial y museos }\end{array}$ & Islas del Egeo (Grecia) \\
\hline Fernández y Ramos (2010) & $\begin{array}{l}\text { Potencial turístico del patrimonio cultural de la Pampa y la cultura } \\
\text { gauche, y el patrimonio minero y ferroviario de los Alemanes del Volga }\end{array}$ & Mar del Plata (Argentina) \\
\hline $\begin{array}{l}\text { López García y Navarro } \\
\text { (2007) }\end{array}$ & Patrimonio arqueológico como dinamizador del turismo cultural & Málaga (España) \\
\hline Navarro (2012) & Revalorización de centros urbanos y creación de equipamientos & $\begin{array}{l}\text { Costa del Sol Occidental } \\
\text { (Málaga, España) }\end{array}$ \\
\hline Smith (2004) & $\begin{array}{l}\text { Autenticidad y patrimonio cultural como elementos principales en la } \\
\text { reestructuración de destinos litorales }\end{array}$ & $\begin{array}{l}\text { Destinos litorales de Reino } \\
\text { Unido }\end{array}$ \\
\hline Vera y Monfort (1994) & $\begin{array}{l}\text { Creación de nuevos productos turísticos basados en los recursos } \\
\text { naturales y culturales }\end{array}$ & $\begin{array}{l}\text { Comunidad Valenciana } \\
\text { (España) }\end{array}$ \\
\hline Vera (2002) & $\begin{array}{l}\text { Creación de productos culturales (conjuntos histórico-monumentales y } \\
\text { rutas e itinerarios) }\end{array}$ & España \\
\hline $\begin{array}{l}\text { Navalón y Rico }\left(2012^{\mathrm{a}} \text {, }\right. \\
2012 \mathrm{~b})\end{array}$ & $\begin{array}{c}\text { Valorización del patrimonio cultural (arqueoturismo, turismo industrial, } \\
\text { elementos singulares del patrimonio cultural) }\end{array}$ & Costa Blanca (España) \\
\hline
\end{tabular}

Fuente: Rico (2014). 
peración, rehabilitación y valorización de elementos construidos (patrimonio histórico); la creación de equipamientos culturales (oferta museística, centros de interpretación); el diseño de circuitos e itinerarios basados en elementos patrimoniales, en la valorización de recursos patrimoniales específicos (patrimonio arqueológico y etnográfico, por ejemplo); potenciación del patrimonio inmaterial; organización de eventos, programación de actividades en torno al patrimonio (teatralización, recreación histórica), entre otros. En algunos casos (Kozac y Martin, 2012; Spilanis y Vayani, 2004), se pretende dar respuesta a las nuevas motivaciones detectadas desde el lado de la demanda que superarían la tradicional complementariedad de los nuevos productos patrimoniales en relación al producto de sol y playa (Vera y Baños, 2010).

En términos generales, en el contexto turístico en el que se localizan los elementos patrimoniales de la Costa Blanca, sólo un reducido grupo podría ser considerado como recurso turístico. Uno de los principales problemas detectados hace referencia a las carencias y limitaciones identificadas en las diferentes dimensiones -cultural, temporal, espacial y económica-, de la accesibilidad (Tresserras y Matamala, 2005; Espinosa 2002ª). Así, para garantizar la accesibilidad cultural e intelectual al patrimonio cultural del destino, es fundamental aplicar la interpretación del patrimonio como la disciplina que permite revelar el significado de los recursos patrimoniales al público en el marco de un proceso de comunicación estratégica desarrollado en un contexto de ocio (Morales y Ham, 2008). En la gran mayoría de los casos, los elementos patrimoniales localizados en este espacio turístico carecen de servicios, soportes y programas de información e interpretación que permitan al visitante una lectura del elemento patrimonial.

Existen también problemas de accesibilidad temporal que se manifiestan en la inadaptación habitual de los horarios y calendarios de acceso de los recursos a la afluencia de visitantes y el incumplimiento de estos horarios en los equipamientos y servicios turísticos asociados cuando existen, que, para el caso de algunos elementos patrimoniales significativos, constituye una evidente limitación para su uso turístico (Rico y Navalón, 2011). A estas limitaciones se añaden problemas que afectan directamente al grado de accesibilidad espacial, es decir, al grado de inclusión y movilidad existente hacia y en el propio recurso patrimonial y en la necesaria atención al público que integra segmentos de visitantes que presentan alguna necesidad particular derivada de la existencia de algún tipo de discapacidad (Espinosa y Bonmatí, 2013). En último lugar, existen problemas relacionados con la accesibilidad económica (mejora del diseño y la información sobre la política de precios, sobre los servicios y productos turísticos patrimoniales) que explican la inexistencia de verdaderos productos turísticos debido a la escasa o nula articulación de mecanismos conducentes a integrar los elementos necesarios para su creación (López y Pulido, 2013).

Las causas de esta realidad de la gestión turística del patrimonio cultural de la Costa Blanca pueden encontrarse en factores de necesidad y escala (Prats, 2011) en el sentido que la activación del patrimonio cultural se ve fuertemente influida por la necesidad de implicación existente en la población local en dicho proceso y su dependencia del patrimonio en la reafirmación de su identidad. En el caso del destino mencionado, es posible afirmar que, hasta el momento, no se han producido verdaderas activaciones patrimoniales encaminadas a generar producto turístico de naturaleza cultural, salvo en algunos casos de ámbito local, quizá porque todavía se tiene una percepción negativa de explotación y abuso 
sobre el patrimonio cultural. En la misma línea, en relación al patrimonio cultural como motor de desarrollo territorial, el escaso grado de uso turístico de los elementos patrimoniales puede deberse al alejamiento de la iniciativa privada en la gestión del patrimonio cultural, a pesar de que en la actualidad se reclama la idoneidad de nuevas formas de afrontar esta gestión donde se encuentren la iniciativa pública y privada (Muñoz, Fuentes y Fayos-Solá, 2012; Greffe, 2005). Por otra parte, la motivación de la demanda desde los orígenes de la actividad turística en este contexto litoral, ha estado centrada en el producto de sol y playa. De ahí que no se haya atendido a las posibilidades turísticas que ofrecía el patrimonio cultural hasta que este producto principal, ha reclamado medidas urgentes para su renovación con fines a mantener su competitividad.

En cuanto al factor de escala (Prats, 2011) generalmente la activación de los elementos patrimoniales se ha limitado a la apertura al público del recurso sin grandes pretensiones de acoger un número importante de visitantes. Esta característica representa un factor que impide el posible desarrollo de productos turísticos patrimoniales porque la mayoría de las activaciones del patrimonio cultural de este espacio responden a iniciativas del gobierno local, con las limitaciones territoriales y económicas que ello implica (inexistencia de personal laboral especializado para atención al visitante; incumplimiento de horarios; escasos recursos para realizar actividades y programas de interpretación, etc.) Al mismo tiempo, la escala local propicia también la repetición de temas en las activaciones patrimoniales en el territorio, a pesar de que la mayoría de los recursos patrimoniales no corresponden a las características de atractivos de gran entidad que por sí solos puedan generar el desplazamiento de los visitantes ${ }^{3}$. (Leno, 1993; Grande, 2001). En este sentido, los recursos patrimoniales compiten entre sí en el territorio (Prats, 2011) debido a que la existencia de elementos patrimoniales no asegura un idéntico grado de atractivo en todos ellos. Por ello no se puede ni se debe aspirar a convertir el conjunto del patrimonio cultural en recurso turístico y en oferta turística cultural. Sin embargo, para el caso objeto de estudio, existe la posibilidad de identificar temas patrimoniales que podrían servir como núcleo para generar productos turísticos en los que se estructuren recursos de distinto grado de relevancia y significado histórico y cultural, bajo el paradigma de la complementariedad patrimonial encaminada a la generación de un producto turístico cultural real ${ }^{4}$.

Por tanto, el patrimonio cultural de la Costa Blanca se caracteriza por tener un papel secundario o complementario dentro de la oferta turística, muy alejado de aquellos recursos que funcionan como el principal motivo de desplazamiento. El patrimonio añade un valor a la imagen del destino pero, en la mayoría de los casos, esta utilización no pasa de ser un mero reclamo promocional. Los procesos de gestión que se han llevado a cabo sobre él habitualmente no han superado cuestiones de ámbito científico (estudio,

3 El patrimonio cultural de la Costa Blanca se situaría en las jerarquías 3, 2 y 1 (Leno, 1993) ya que no existen recursos patrimoniales de un grado de atractivo superior (jerarquías 4 y 5), con suficiente relevancia en ellos mismos o en conjunto con otros atractivos cercanos, para atraer a una corriente de visitantes nacionales y extranjeros.

4 Por ejemplo, las enormes posibilidades detectadas en el patrimonio arqueológico de este espacio, en el que el Museo Arqueológico Provincial de Alicante (en adelante, MARQ) podría actuar como el elemento de atracción principal que se complementaría con la red de yacimientos musealizados y museos arqueológicos, existente en la provincia de Alicante. Cabe recordar que el MARQ fue declarado Mejor Museo Europeo del Año 2004 por el European Museum Forum. 


\section{Mapa 1 \\ ÁREAS TEMÁTICAS DE POTENCIALIDAD \\ TURÍSTICA CULTURAL EN LA COSTA BLANCA}

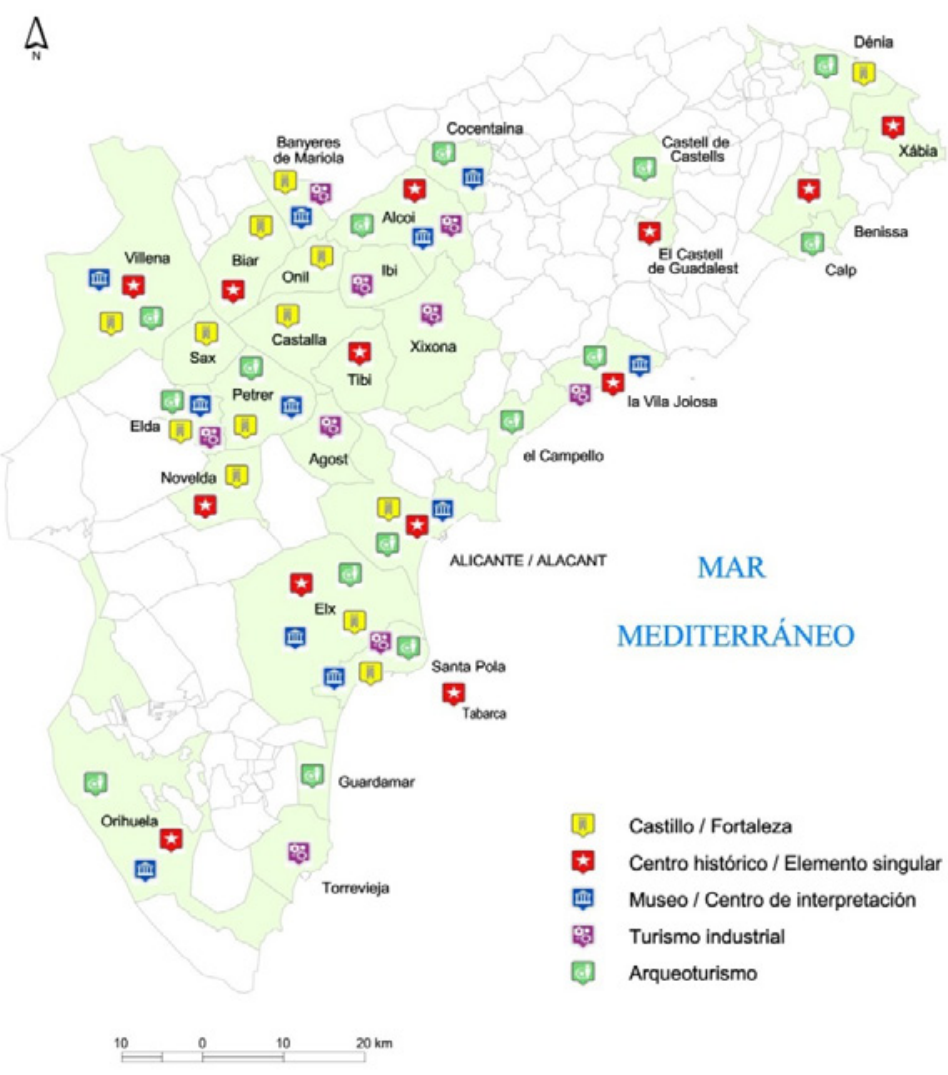

Fuente: Rico (2014).

conservación, protección), para encaminarse a la presentación, comunicación, difusión e interpretación del valor y el significado del elemento al público visitante (Querol, 2010; Ballart y Tresserras, 2001).

En el siguiente apartado de análisis se podrá comprobar que determinados elementos que actúan como atractivo turístico para el fenómeno excursionista de la ociurbe de Benidorm, no presentan un grado de atractivo patrimonial relevante e incluso, a veces, este componente no existe. En contraposición, se han identificado otros elementos del conjunto patrimonial que, situados en la misma área de influencia territorial y turística, podrían generar productos turísticos de naturaleza patrimonial indiscutible. Con ello se confirma que la construcción de recursos turísticos de escasa autenticidad patrimonial viene generada por la propia mirada del turista, a pesar del dudoso componente patrimonial que es intrínseco al elemento en cuestión. 


\section{EL MODELO DE DESARROLLO TURÍSTICO DE LA PROVINCIA DE ALI- CANTE: ALGUNOS INDICADORES DE SU POLARIZACIÓN EN LA FRANJA LITORAL}

Es un hecho evidente que el turismo alicantino depende de forma esencial del aprovechamiento de los recursos de sol y playa, de manera que, como se ha señalado, esta actividad ha contribuido a la agudización de los contrastes económicos y demográficos entre este espacio litoral y el interior provincial. En los veinte municipios costeros residen 1.129.054 habitantes (INE, 2014) es decir, el 60,4\% de la población provincial. La franja litoral recibe la mayor parte de las inversiones públicas y privadas, cuenta con una mayor dotación de infraestructuras y es el ámbito donde se ha producido la mayor transformación del suelo, de manera que se configura una gran conurbación fruto de los desarrollos urbanos lineales con el resultado de que el $80 \%$ del litoral alicantino está urbanizado (Vera y Baños, 2001).

Desde el punto de vista sectorial, esa polarización del turismo sobre el litoral justifica el peso abrumador de la oferta de los municipios litorales y explica la configuración del espacio turístico de la provincia.

La provincia de Alicante posee más de la mitad de la oferta de alojamiento reglado de la Comunidad Valencia: el $55 \%$ de plazas hoteleras, $47 \%$ en apartamentos, $41 \%$ en campings y $23 \%$ en plazas en casas rurales. Esa oferta se concentra de manera clara en el ámbito litoral y en algunos municipios prelitorales de las comarcas de la Marina Baixa y el Bajo Segura. Por otra parte, a esta oferta legal habría que sumar el ingente volumen de alojamiento que supone la oferta no reglada en forma de viviendas y apartamentos que configura la realidad de la mayoría de estos municipios turísticos y especializados en segundas residencias, cuyas dinámicas sectoriales se distinguen de manera absoluta de las de los municipios con potente oferta hotelera. Si bien resulta harto difícil realizar una cuantificación precisa del volumen de este tipo de oferta, aproximadamente el litoral y algunos municipios prelitorales de la Costa Blanca pueden concentrar en torno a un millón de estas plazas de alojamiento. Por otra parte, los datos de demanda vienen a confirmar, lógicamente, en esa tendencia: sólo el 2,2\% de las pernoctaciones hoteleras tienen lugar en municipios de interior y únicamente el $0,3 \%$ de las pernoctaciones corresponden a alojamientos en casas rurales.

En este modelo territorial-turístico, la ociurbe de Benidorm presenta unas características únicas en cuanto a su configuración como destino turístico, en el papel que juega su jerarquía urbana en la influencia sobre el entorno comarcal.

Benidorm se ha configurado como el principal destino turístico del Mediterráneo español. Desde mediados del pasado siglo XX el turismo y los servicios vinculados son el motor de las dinámicas sociales, económicas y demográficas de la ciudad. La estructura económica está claramente especializada en el turismo y el sector servicios gira en torno a esta actividad, mientras que el crecimiento demográfico asociado al turismo es la causa de su posición en el sistema urbano comarcal y regional. (69.010 habitantes en 2014, el $36 \%$ originario de otras regiones españolas y el $28 \%$ extranjeros).

Se trata de un destino basado esencialmente en el sol y playa (posee más de cinco kilómetros de playas urbanas en exposición meridional, alrededor de 2.800 horas de sol 
anuales, temperaturas invernales suaves). La imagen de la ciudad va asociada, desde los años sesenta del siglo XX, a una tipología edificatoria en altura que ha conformado una trama urbana donde la densidad, la verticalidad y la concentración son sus características esenciales. Cuenta una potente planta de alojamiento reglado (Fig. 1) con una fuerte especialización hotelera (el 32\% del total de las plazas de la Comunidad Valenciana) especialmente en categorías medias (50,9\% en 3 estrellas) y medias-altas (36\% en 4 estrellas). El subsistema recreativo se caracteriza por su diversidad, desde ofertas generalistas basadas en el comercio, la restauración y el ocio nocturno a instalaciones recreativas especializadas. La comercialización del destino ha dependido históricamente de touroperadores

\section{Figura 1 \\ INDICADORES TURÍSTICOS DE LA PROVINCIA DE ALICANTE POR ZONAS (2014)}

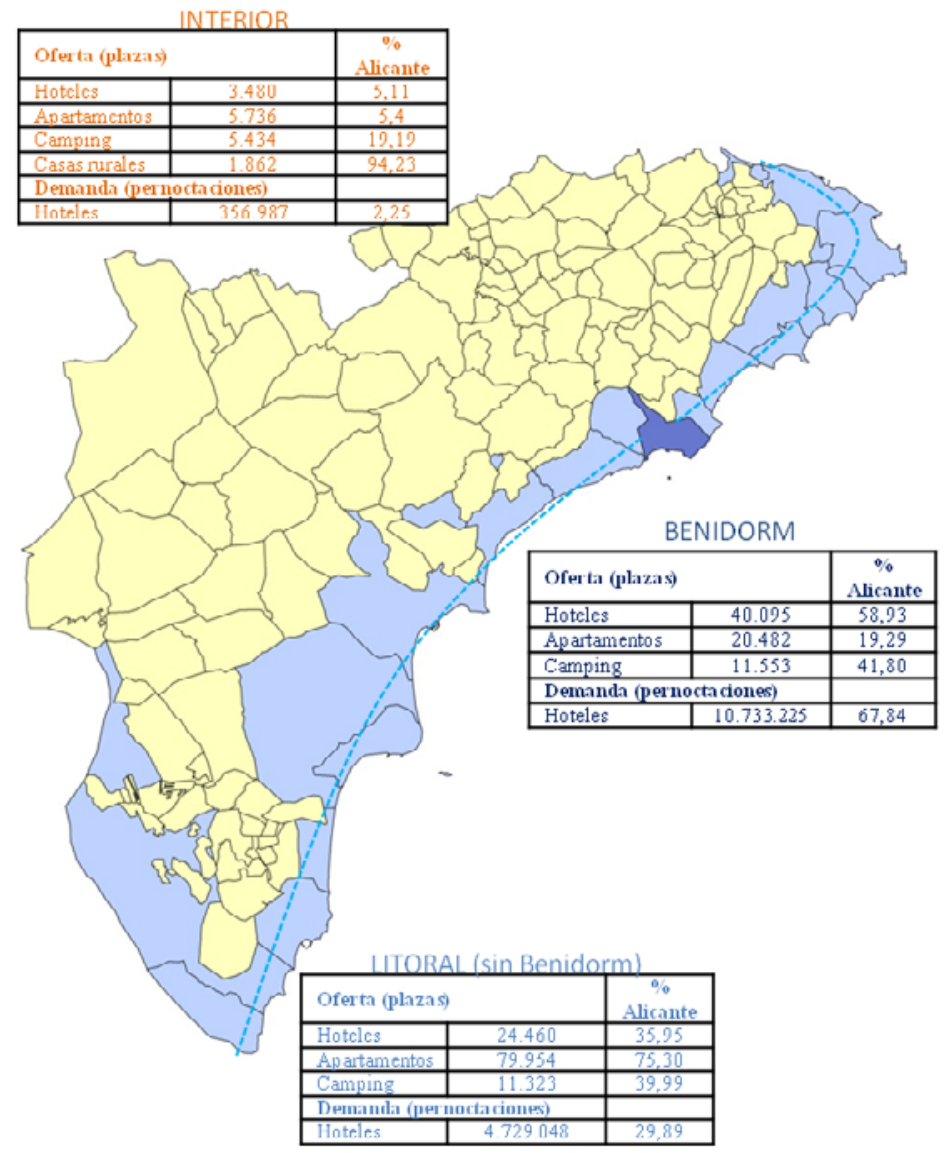

Fuente: INE, Agencia Valencia de Turisme. Elaboración propia. 
europeos, esencialmente británicos, a través de la venta de paquetes si bien el crecimiento del turismo independiente, la comercialización en internet y el efecto de las compañías aéreas de bajo coste, han supuesto cambios notables sobre los modos de producción turística tradicionales que imponía el sistema de la turoperación, con implicaciones diversas (Vera y Baños, 2010). La demanda se reparte aproximadamente entre turistas españoles y extranjeros: en 2014 se generaron casi 15 millones de pernoctaciones en establecimientos reglados, producidas por 2.260.000 visitantes; el 50,9\% de las hoteleras fueron de turistas españoles y el $49 \%$ de extranjeros, con una fuerte presencia de británicos (35\% del total).

Esta auténtica ciudad del ocio ha evolucionado en un contexto de continua adaptación a los ciclos y fases evolutivas del turismo: se ha producido la renovación de su planta hotelera, afrontado actuaciones de modernización de la escena urbana, introducción de mejoras en la gestión ambiental del destino y la creación de nuevas ofertas y equipamientos de ocio.

\section{BENIDORM Y LA FUNCIONALIDAD TURÍSTICA DE LOS ELEMENTOS PATRIMONIALES DE INTERIOR}

Una de las características que definen a Benidorm como destino de turismo de masas es el intenso dinamismo en cuanto al consumo de espacio y tiempo realizado por los turistas. En Benidorm el turista pasa fuera de su alojamiento al menos quince horas por día (Iribas, 2000), entre tres y cinco más de las que emplean en estar fuera de su residencia los veraneantes del resto de municipios de la Comunidad Valenciana.

El consumo de espacio y tiempo en la prácticas recreativas de los visitantes de Benidorm se centran en el paseo, las playas, compras, establecimientos de restauración y ocio nocturno y la práctica de algún deporte (Ayuntamiento de Benidorm; Soares, 2012), son actividades que Stock incluye entre las modalidades de «reposo» y «juego» (Stock, 2003) características de la etapa de producción turística fordista. Sin embargo, diferentes indicadores ponen de manifiesto que, en un contexto global caracterizado por importantes cambios en la demanda turística internacional, el potencial que el patrimonio cultural puede tener para el desarrollo de nuevas modalidades recreativas de «descubrimiento» según Stock y como elemento a integrar en nuevas líneas de diversificación del producto de sol y playa. En este sentido, los resultados extraídos por el Plan de Valorización del Patrimonio Cultural Costa Blanca Cultura, (Diputación Provincial de Alicante, 2008-2013) muestran que el

5 El Plan de Valorización del Patrimonio Cultural de la provincia de Alicante Costa Blanca Cultura fue un proyecto de investigación financiado por el Patronato Provincial de Turismo Costa Blanca en el año 2008 realizado en el seno del Instituto Universitario de Investigaciones Turísticas de la Universidad de Alicante.

A través de un cuestionario distribuido entre las oficinas de turismo pertenecientes a la red Tourist Info, se pudo comprobar el interés que mostraron los visitantes que acudieron a este servicio turístico con el objetivo de obtener información relativa al patrimonio cultural del lugar visitado. Así, se analizaron cuestiones relativas al grado de importancia concedido por el visitante, el uso turístico de los elementos patrimoniales locales, la valoración sobre aspectos relacionados con la señalización y adaptación de los recursos culturales a diferentes tipos de público, entre otros. Por otra parte también resulta significativa la información a propósito del grado de conocimiento de la oferta turística del destino así como los aspectos más demandados en relación a los elementos patrimoniales por parte del visitante. Para el análisis de la demanda turística en relación al interés por el patrimonio cultural provincial, se distribuyó el cuestionario mencionado a las sesenta y siete oficinas de turismo que formaban parte de dicha red. Se recibieron sesenta y dos cuestionarios que representaban la opinión y valoración de los informadores turísticos de treinta y cuatro municipios. 


\section{Figura 2}

\section{GRADO DE IMPORTANCIA ATRIBUIDO POR LA DEMANDA AL PATRIMONIO CULTURAL EN LA COSTA BLANCA}
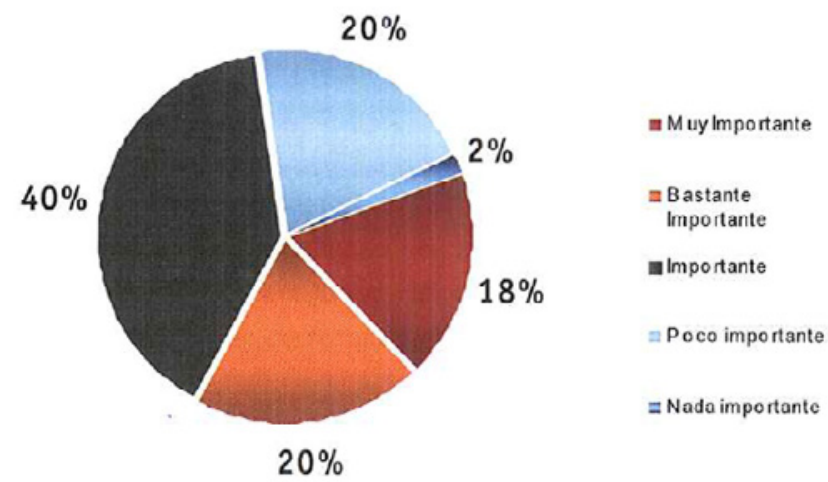

= Nada importante

Fuente: Plan Costa Blanca Cultura.

$78 \%$ de los informantes consideró que el patrimonio cultural es un componente importante en el municipio en cuestión, en mayor o menor grado, siendo el porcentaje de opiniones contrarias muy reducido.

Asimismo, en el marco del proyecto en el que se incardina este trabajo, se realizó una encuesta (mayo-junio de 2014) entre turistas alojados en hoteles de Benidorm orientada a conocer su comportamiento espacial. El 20\% de los entrevistados manifestó haber realizado, o tener previsto hacerlo, alguna excursión en el entorno comarcal con una motivación cultural.

En este sentido, Benidorm no posee una diversidad suficiente de recursos turísticos patrimoniales que pudiera actuar como base de las nuevas modalidades recreativas mencionadas, de ahí que resulte necesario atender a las posibilidades que ofrece el ámbito regional para explicar los componentes del fenómeno excursionista actual, que ha permanecido prácticamente inmutable desde los orígenes de la actividad, así como las potencialidades que ofrecen determinados elementos patrimoniales para su uso recreativo.

\subsection{La dimensión territorial de las excursiones turísticas: tipología de los recursos, accesibilidad y concentración de la demanda}

El consumo de excursiones en áreas próximas al destino de alojamiento es una de las fórmulas más clásicas de recreación complementaria en el modelo turístico de sol y playa masivo. Prácticamente todas las regiones turísticas del Mediterráneo y archipiélagos disponen de este tipo de ofertas de ocio como componentes complementarios de las vacaciones en el destino elegido. A pesar de ello, apenas han merecido atención en los enfoques científicos del turismo y especialmente desde la óptica del territorio. 
Las excursiones en destino, excursiones organizadas facultativas, forman parte de los servicios que son ofertados por los propios operadores turísticos mayoristas a sus clientes dentro de los paquetes. Estas excursiones habitualmente se contratan en destino y tienen un carácter opcional convirtiéndose en verdaderas ofertas complementarias de los paquetes turísticos. En el caso de la Costa Blanca las principales agencias mayoristas que operan en la zona, TUI, Thomas Cook, MyTravel o COSMOS, incorporan estas ofertas dentro de la configuración de sus paquetes. En ocasiones los turoperadores han incluido la gestión de estos productos en los departamentos o unidades específicas dedicadas a las ventas en destino. Es el caso de TUI España, compañía integrada en el principal operador turístico mundial, el grupo TUI Travel PLC. La división para España de TUI gestionó durante el año 2008 más de dos millones de excursiones en aquellos destinos donde opera directamente ${ }^{6}$-Tenerife, Fuerteventura, Gran Canaria, Lanzarote, Jerez (Costa de la Luz), Torremolinos (Costa del Sol), Benidorm (Costa Blanca) y Palma de Mallorca-. En última instancia el ensamblaje de los diferentes recursos y servicios que componen las visitas guiadas así como la organización y el desarrollo de las mismas corre a cargo de agencias locales receptivas que crean el producto en función de los requerimientos de los operadores mayoristas, si bien la distribución y venta de las mismas no es exclusiva para los clientes de esas mayoristas.

Se trata de una oferta recreativa incorporada al producto de sol y playa desde las primeras fases del desarrollo de la tercera periferia del ocio en los años sesenta y setenta del pasado siglo XX, con la que se trata de complementar la oferta básica del «sol y playa» con elementos y ofertas añadidas relacionadas con el folklore y cultura local cargados de un innegable tipismo (Cuadro 2) lo que venía a dotar de un valor añadido al producto básico de sol y playa. Las excursiones más demandadas en esas primeras fases incluían la visita a las principales ciudades de la provincia (Alicante, Elche), salidas a lugares y poblaciones próximas a Benidorm sustentadas en la existencia de variados recursos con valor natural y/o cultural (El Castell de Guadalest, Fuentes del Algar), actividades pintorescas y cargadas de tipismo o, superando el ámbito comarcal, visitas a ciudades de otras provincias y regiones (Valencia, Murcia, Madrid, Toledo). La oferta de excursiones así como los recursos básicos y destinos incluidos en las mismas, se ha ampliado sobre esa base inicial al tiempo que desde el punto de vista del comportamiento de la demanda se detecta un incremento de número de excursiones realizadas.

Por tanto, una de las primeras variables a considerar en la articulación de los flujos de excursionismo organizado es el factor de atracción de los recursos y destinos. Ya se ha apuntado la tipología de los recursos que se insertan en la articulación de las excursiones: patrimonio natural y cultural localizado, paisaje, tipismo, prácticas recreativas y deportivas de baja intensidad. Asimismo se introducen componentes inmateriales del patrimonio cultural, así como aspectos que contribuyen a la construcción de imágenes turísticas identificadas con lugares «auténticos» en el contexto mediterráneo (Donaire, 2008). Se trata, en todo caso, de un patrimonio turístico que tiene en el traspaís de la provincia un amplio repertorio de recursos potencialmente integrable en esos circuitos. En la mayor parte de los casos el patrimonio cultural es el elemento de diferenciación de

6 Dossier de prensa de TUI España 2009 extraído de Baños (2009). 


\section{Cuadro 2}

EXCURSIONES REALIZADAS POR LOS TURISTAS DE LA COSTA BLANCA \% DE RESPUESTAS POSITIVAS

\begin{tabular}{|l|r|r|c|}
\hline \multicolumn{1}{|c|}{ Destinos } & $\mathbf{1 9 7 2 - 1 9 7 4}$ & $\begin{array}{c}\text { Verano } \\
\mathbf{2 0 0 4}\end{array}$ & $\begin{array}{c}\text { Verano } \\
\mathbf{2 0 1 3}\end{array}$ \\
\hline Alfaç del Pi & & 14,2 & 25,1 \\
\hline Alicante & 13,77 & 25,3 & 44,7 \\
\hline Altea & & 22,4 & 46,0 \\
\hline Calp & 1,70 & 17,6 & 38,6 \\
\hline Denia & & 8,2 & 20,1 \\
\hline Elche & 7,48 & 4,6 & 20,1 \\
\hline Finestrat & 3,91 & 15,3 & 21,7 \\
\hline Fuentes del Algar & 6,80 & 11,6 & 20,3 \\
\hline Guadalest & 7,48 & 9,8 & 30,9 \\
\hline La Nucía & & & 14,9 \\
\hline Limón Express & 2,04 & & \\
\hline Madrid-Toledo & 1,02 & & \\
\hline Murcia & 1,70 & & \\
\hline Paseo en burro en Callosa d'en Sarrià & 1,36 & & \\
\hline Finestrat & & 15,3 & 21,7 \\
\hline Polop & & & 17,2 \\
\hline Valencia & 5,10 & 8,0 & 21,9 \\
\hline Villajoyosa & & 13,2 & 28,2 \\
\hline Otros & & 3,7 & 14,7 \\
\hline
\end{tabular}

Fuente: Gaviria, Iribas, Sabbah y Sanz (1975). Estudio sobre hábitos turísticos, opiniones y valoración de la oferta turística de Benidorm, Ayuntamiento de Benidorm, 2005 y 2014.

los lugares de propuestos y que comúnmente sirven también como imagen promocional. Existen destinos como La Vila Joiosa, Alicante, Elx y Valencia que cuentan con recursos patrimoniales de suficiente relevancia y entidad como para actuar como reclamo. En otros casos, en los que los referentes patrimoniales no son tan identificables, se potencia el patrimonio concentrado como en Altea y Polop, en los que se hace referencia al casco antiguo por el atractivo de su trama y emplazamiento, que otorga una imagen típica de pueblo mediterráneo.

No obstante, a pesar de esa ampliación y cierta diversificación en los recursos puestos en valor, resulta interesante por ejemplo la introducción del componente enológico como motivador de las excursiones que ha evolucionado hasta incorporar visitas a reputadas bodegas, los circuitos de excursiones organizadas en la provincia de Alicante poseen un marco territorial limitado. Con base en Benidorm, la mayoría de las rutas se ciñen al espacio inmediato del traspaís del gran destino turístico de la Costa Blanca, en las comarcas de la Marina Baixa (Callosa d'en Sarrià, Polop, Castell de Guadalest) y la Marina 


\section{Cuadro 3}

\section{EL USO DEL TERRITORIO EN LAS PROPUESTAS DE EXCURSIONES DESDE EL DESTINO BENIDORM}

\begin{tabular}{|c|c|c|c|}
\hline $\begin{array}{l}\text { LUGAR DE } \\
\text { INTERÉS }\end{array}$ & $\begin{array}{l}\text { DISTANCIA } \\
\text { BENIDORM }\end{array}$ & RECURSOS DESTACADOS & $\begin{array}{c}\text { Imagen promocional } \\
\text { asociada }\end{array}$ \\
\hline Cala de Finestrat & $5 \mathrm{~km} . / 10 \mathrm{~min}$. & Paseo marítimo y mercadillo & $\begin{array}{l}\text { Puig Campana, casco } \\
\text { antiguo }\end{array}$ \\
\hline Alfaç del Pi & $6 \mathrm{~km} . / 10 \mathrm{~min}$. & Paseo marítimo y mercadillo & \\
\hline Altea & $10 \mathrm{~km} . / 25 \mathrm{~min}$. & $\begin{array}{l}\text { Paseo marítimo, casco antiguo, galerías de } \\
\text { arte y artesanía }\end{array}$ & $\begin{array}{l}\text { Casco antiguo } \\
\text { Puerto deportivo }\end{array}$ \\
\hline La Nucía & $10 \mathrm{~km} . / 25 \mathrm{~min}$. & Casco antiguo, parajes naturales, rastro & \\
\hline Polop & $12 \mathrm{~km} . / 25 \mathrm{~min}$. & $\begin{array}{l}\text { Plaza de los Chorros, vistas desde el } \\
\text { cementerio }\end{array}$ & \\
\hline La Vila Joiosa & $14 \mathrm{~km} . / 25 \mathrm{~min}$. & $\begin{array}{l}\text { Casas pintadas, puerto pesquero, Museo del } \\
\text { Chocolate, mercadillo }\end{array}$ & Casas pintadas \\
\hline Fuentes del Algar & $18 \mathrm{~km} . / 30 \mathrm{~min}$. & $\begin{array}{l}\text { Nacimiento del río Algar, rutas senderistas y } \\
\text { jardín botánico }\end{array}$ & Fuentes del Algar \\
\hline Calp & $23 \mathrm{~km} . / 25 \mathrm{~min}$. & $\begin{array}{l}\text { Parque Natural del Peñón de Ifach, puerto } \\
\text { pesquero, Baños de la Reina, casco antiguo }\end{array}$ & Peñón de Ifach \\
\hline $\begin{array}{l}\text { Castell de } \\
\text { Guadalest }\end{array}$ & $23 \mathrm{~km} . / 35 \mathrm{~min}$. & Castillo de San José, museos & $\begin{array}{l}\text { Pantano } \\
\text { Enclave del casco } \\
\text { antiguo }\end{array}$ \\
\hline Tárbena & $27 \mathrm{~km} . / 50 \mathrm{~min}$. & Paisaje, gastronomía & \\
\hline Alicante & $45 \mathrm{~km} . / 45 \mathrm{~min}$. & $\begin{array}{l}\text { Casco antiguo, San Nicolás, Castillo de } \\
\text { Santa Bárbara, Explanada, puerto, MARQ y } \\
\text { Museo de las Hogueras }\end{array}$ & $\begin{array}{l}\text { Vista del puerto desde } \\
\text { el Castillo de Santa } \\
\text { Bárbara }\end{array}$ \\
\hline Jálon & $40 \mathrm{~km} . / 45 \mathrm{~min}$. & Paisaje, bodegas & \\
\hline Penáguila & $44 \mathrm{~km} . / 70 \mathrm{~min}$. & Safari Aitana & \\
\hline Busot (Cuevas) & $45 \mathrm{~km} . / 50 \mathrm{~min}$. & Coves de Canelobre & \\
\hline Dénia & $51 \mathrm{~km} . / 50 \mathrm{~min}$. & Castillo y Museo Arqueológico, mercadillo & \\
\hline Elx & $70 \mathrm{~km} . / 55 \mathrm{~min}$. & $\begin{array}{l}\text { Palmerales y centro histórico, Calahorra, } \\
\text { Basílica de Santa María, Ayuntamiento, } \\
\text { Convento de la Mercé }\end{array}$ & Palmeral \\
\hline Novelda & $71 \mathrm{~km} . / 70 \mathrm{~min}$. & $\begin{array}{l}\text { Museo casa modernista, santuario } \\
\text { modernista }\end{array}$ & \\
\hline Santa Pola & $72 \mathrm{~km} . / 65 \mathrm{~min}$. & Salinas, acuario, castillo fortaleza XVI & \\
\hline Tabarca & & $\begin{array}{l}\text { Paisaje, playas, patrimonio arquitectónico } \\
\text { XVIII }\end{array}$ & \\
\hline Villena & $94 \mathrm{~km} . / 75 \mathrm{~min}$. & Tesoro de Villena, bodegas & \\
\hline Valencia & $140 \mathrm{~km} . / 110 \mathrm{~min}$. & $\begin{array}{l}\text { Catedral, Micalet, Ciudad de las Artes y las } \\
\text { Ciencias, Palacio de Congresos }\end{array}$ & $\begin{array}{l}\text { Ciudad de las Artes y } \\
\text { las Ciencias }\end{array}$ \\
\hline
\end{tabular}

Elaboración propia a partir de fuentes y materiales de promoción turística. 
Alta (Tárbena, Benissa, Jalón), se trata de puntos de visitas que se articulan en sentido norte-sur a través de la Autopista AP7 y la carretera Nacional 332 a partir de las cuales las diferentes carreteras comarcales dan acceso hacia las poblaciones del interior, en un dirección perpendicular al eje costero, de manera que se da continuidad a las excursiones mediante paradas que exigen no más de media hora de trayecto entre cada una de ellas.

El límite sur del «espacio útil» para el excursionismo de touroperador lo marcan destinos y recursos del Área Metropolitana de Alicante-Elx (Alicante Compras, Busot, Elx, Santa Pola, Isla de Tabarca), en el borde la isócrona de una hora (sin paradas) definido entre Benidorm y Santa Pola. En efecto, esa isócrona de una hora de viaje (entre 35 y 70 kilómetros de trayecto) se marca como frontera que acota el área de explotación de las excursiones turísticas que operan desde Benidorm. La variable accesibilidad se muestra, por tanto, como una de las claves de interpretación en la inserción de recursos en estos sistemas de visitas, de manera que quedan al margen de los flujos excursionistas organizados amplias zonas en las comarcas del Bajo Segura y de interior, Alto y Medio Vinalopó, salvo la puntual visita a las localidades de Villena y Novelda de reciente incorporación al catálogo de excursiones, L'Alcoià y El Comtat.

Sin embargo, potencialidad de los recursos y accesibilidad no constituyen condiciones suficientes para la incorporación de nuevos recursos. Además de la adecuación y puesta en valor de los recursos para la visita turística, el excursionismo exige de una cierta masa crítica de aparato comercial y de servicios -restauración, compras- del que muchas de las poblaciones de interior carecen. Desde la perspectiva empresarial de los organizadores, agencias de viajes y receptivos, la ausencia de esa oferta de servicios que complemente el consumo del recurso se considera uno de los frenos más importantes en cuanto a la ampliación y renovación de la oferta de excursiones, así como la deficiencia en señalización e información turística.

Estos factores determinan que, a pesar de las potencialidades de las áreas de interior, exista una muy baja innovación en la creación de las ofertas, limitadas desde hace años prácticamente a los mismos circuitos y lugares. Como se ha señalado, el mapa de las excursiones turísticas permanece restringido a la isócrona de 45-50 minutos en el entorno septentrional de Benidorm, el área metropolitana Alicante-Elx y las capitales extra provinciales. El primero de esos espacios, limitado por esa isócrona de 45-50 minutos, concentra la mayor parte de los lugares de visita incluidos en las excursiones y concretamente aquellos particularmente más exitosos, como la localidad de Castell de Guadalest y el paraje de las Fuentes del Algar ${ }^{7}$, en el municipio de Callosa d'en Sarrià. Se trata de poblaciones y entornos sometidos en ocasiones a una excesiva presión por frecuentación de ese excursionismo que puede llegar a generar amenazas sobre los recursos -degradación, banalización de los mismos, musealización de los centros de población- o sobre las propias sociedades locales, derivadas de la excesiva especialización económica y monofuncionalización sectorial en torno al excursionismo.

Por otra parte, la carencia de técnicas e instrumentos de gestión del turismo tanto a escala local -evaluación de potencialidades de los recursos, estudios de capacidad de carga

7 La Oficina de Turismo de Castell de Guadalest atendió en 2014 prácticamente 50.000 consultas de visitantes. El paraje de las Fuentes del Algar recibió en 2013 más de 221.00 visitantes, el $60 \%$ entre los meses de julio y agosto. 


\section{Figura 3 \\ ESQUEMA DE LAS PRINCIPALES EXCURSIONES TURÍSTICAS CON BASE EN BENIDORM}

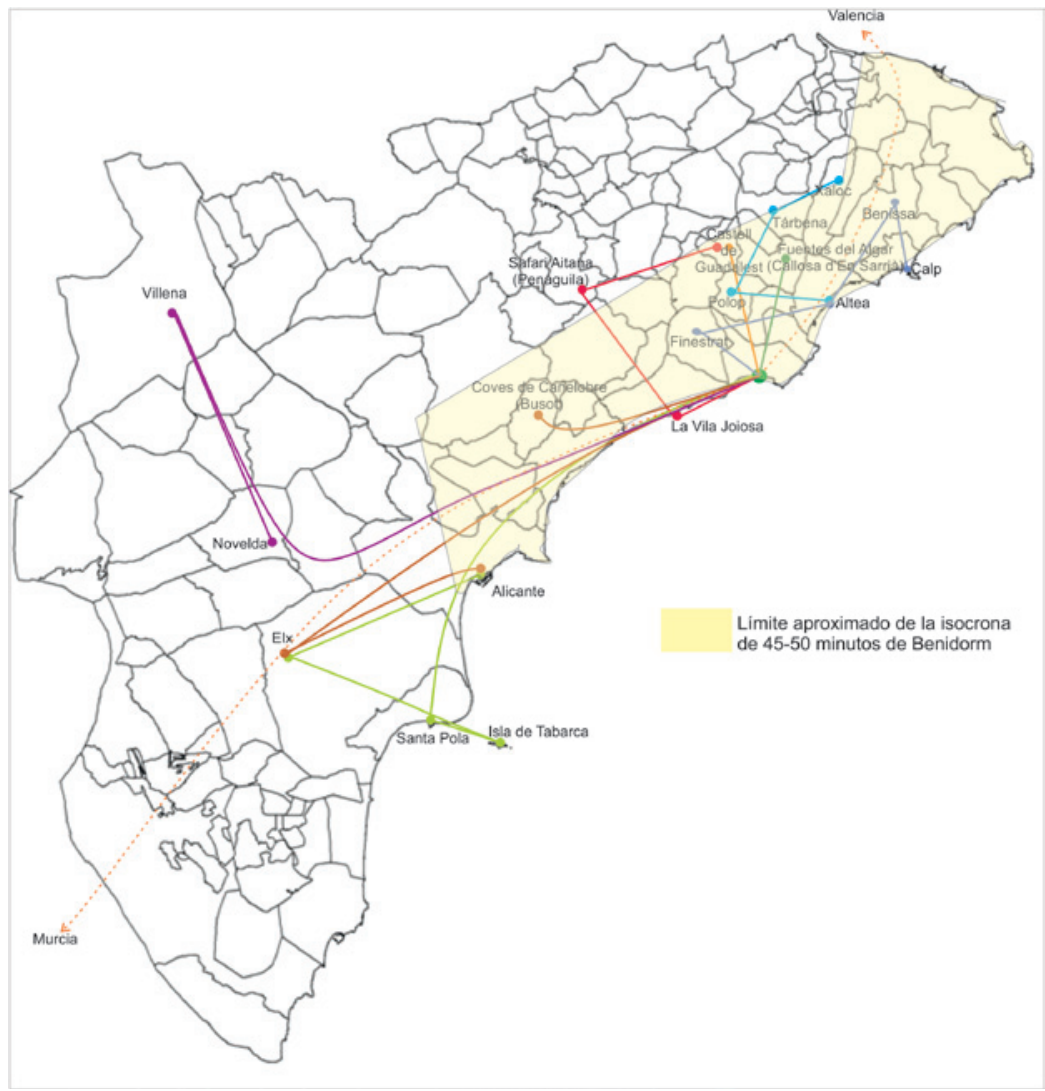

Elaboración propia a partir de los catálogos de excursiones de operadores de Benidorm.

y gestión de flujos, técnicas de interpretación- como subregional, -creación de marcos institucionales de colaboración entre municipios, órganos de gestión mancomunadosprofundizan en esas debilidades y amenazas

\section{ESTUDIOS DE CASOS. EL CASTELL DE GUADALEST Y LA VILA JOIOSA: REALIDAD Y POTENCIALIDAD TURÍSTICA PATRIMONIAL EN EL CON- TEXTO DE LA MARINA BAIXA}

El primer caso de estudio seleccionado es el municipio de El Castell de Guadalest, el principal centro de excursionismo desde el origen de esta actividad, y la Vila Joiosa, municipio limítrofe con Benidorm que, por su tradición histórica, y a pesar de su ele- 
vada concentración de elementos patrimoniales pertenecientes a distintas épocas, no ha sido objeto de uso turístico con la misma intensidad que el caso anterior. Además, esta importancia se ha visto potenciada por la existencia de una estrategia de desarrollo local centrada en los últimos años en la recuperación y valorización del conjunto patrimonial. En este sentido, el antiguo Museo Arqueológico y Etnográfico ha liderado estas actuaciones, hasta el punto de que su remodelación y transformación en el Vilamuseu, convertirá a este equipamiento cultural en un referente museológico donde la interpretación del patrimonio es la disciplina sobre la que se está gestando el proyecto museográfico y las actividades orientadas al público.

En el primer caso, el Castell de Guadalest es un municipio de interior de la comarca de la Marina Baixa, de origen musulmán, caracterizado por el emplazamiento de su conjunto histórico declarado BIC sobre una superficie montañosa y abrupta. Este conjunto histórico se divide en dos partes, la villa fortificada en la cota más elevada, y el arrabal, situado en el valle. La fisonomía del conjunto histórico corresponde a la época de fundación aunque los relativos atractivos patrimoniales que posee (sistema de murallas, el castillo, casas señoriales y edificios civiles) datan a partir del siglo XVI.

El uso turístico que se ha realizado de este enclave se debe a la imagen de tipismo, folclorismo y mediterraneidad de este municipio que lo han convertido en un hito turístico que se asocia con la esencia de «lo auténtico» ${ }^{8}$. Debido a la especialización turística de su estructura económica, en este municipio se ha generado una oferta de iniciativa privada de escaso grado de autenticidad patrimonial basada en la creación de museos de temática muy variada que complementa la oferta turística local. De esta oferta museística existente, únicamente el Museo Etnológico está reconocido como tal por la normativa autonómica del patrimonio cultural valenciano de 1998. El resto de museos no comparten las funciones museísticas atribuidas por la ley, a pesar de que son objeto de promoción como tales.

A la vista de lo expuesto, se puede observar que la temática museística se aleja de los contenidos habituales de estos espacios patrimoniales. Sin embargo, su localización en un entorno singular permite deducir que genera un importante volumen de visitantes, según las comprobaciones realizadas en el trabajo de campo ${ }^{9}$.

En una situación opuesta a la anterior en cuanto a la relevancia y magnitud de su patrimonio cultural, se encuentra el segundo estudio de caso, la Vila Joiosa, municipio limítrofe con Benidorm cuya importancia histórica en el contexto de la Marina Baixa ha dado lugar a un volumen significativo de elementos patrimoniales, originados fundamentalmente, desde época romana. Este hecho la convierte en una de las ciudades con más concentración de BIC en la Comunidad Valenciana. Su protagonismo histórico tiene su origen en el relevante papel de su poblamiento y de su puerto comercial en la comarca y en

8 En enero de 2015 Guadalest entró a formar parte de la marca Los Pueblos más bonitos de España, previo cumplimiento de algunos requisitos, entre los que destaca poseer un patrimonio arquitectónico o natural certificado por la administración local, de calidad urbanística y arquitectónica. Además, se ha de demostrar la existencia de una política de valoración patrimonial entre cuyas acciones se contemplan la valorización, desarrollo, promoción y animación del patrimonio local. Fecha de último acceso: 7/7/2015. http://www.lospueblosmasbonitosdeespana.org/comunidad-valenciana/guadalest

9 Para la realización de esta investigación, se solicitó reiteradamente información sobre volumen de visitantes en la oferta museística del municipio. Debido al carácter fiscal de estos datos, los responsables se mostraron reticentes y no aportaron la información requerida por los investigadores. 


\section{Cuadro 4 \\ OFERTA MUSEÍSTICA DE EL CASTELL DE GUADALEST}

\begin{tabular}{|c|c|}
\hline MUSEO & TITULARIDAD Y TEMÁTICA \\
\hline $\begin{array}{r}\text { Museo Belén y Casitas de } \\
\text { Muñecas }\end{array}$ & $\begin{array}{l}\text { Privado } \\
\text { Casas de muñecas, belén ecológico y juguetes } \\
\text { antiguos }\end{array}$ \\
\hline Museo Etnológico & $\begin{array}{l}\text { Privado. Reconocido por la normativa autonómica } \\
\text { Etnología-Vida de los habitantes de la Vall de } \\
\text { Guadalest }\end{array}$ \\
\hline Museo Histórico Medieval & $\begin{array}{l}\text { Privado } \\
\text { Piezas e instrumentos de tortura y pena capital }\end{array}$ \\
\hline Museo Microgigante & $\begin{array}{l}\text { Privado } \\
\text { Objetos en miniatura aumentados }\end{array}$ \\
\hline Museo Microminiaturas & $\begin{array}{l}\text { Privado } \\
\text { Objetos en miniaturas }\end{array}$ \\
\hline Museo Municipal Casa Orduña & $\begin{array}{l}\text { Público } \\
\text { Etnografía. Familia nobiliaria. }\end{array}$ \\
\hline Museo de Saleros y Pimenteros & \begin{tabular}{|l} 
Privado \\
Colección de estas piezas (20.000)
\end{tabular} \\
\hline $\begin{array}{r}\text { Museo Vehículos Históricos } \\
\text { Valle de Guadalest } \\
\end{array}$ & \begin{tabular}{|l} 
Privado \\
Vehículos clásicos
\end{tabular} \\
\hline
\end{tabular}

Elaboración propia a partir de http://www.guadalest.es/museos.

la historia de la navegación del Mediterráneo occidental ya que las condiciones naturales del entorno resultaban idóneas para el refugio y fondeadero de barcos desde época ibérica y, fundamentalmente, moderna y contemporánea (Espinosa, 2011) ${ }^{10}$.

El interés del caso de la Vila Joiosa radica en la manifiesta preocupación por parte del gobierno local (Concejalía de Cultura y Patrimonio Histórico) por la gestión del patrimonio local desde una perspectiva integrada, con el objetivo principal de crear un motor cultural y económico de primer orden para la ciudad a través del patrimonio histórico (Espinosa, 2011a). Así, en el año 2008 se redacta el Plan Estratégico del Patrimonio Histórico de la ciudad, en el que se reúne a diferentes administraciones, entidades, propietarios, empresas, patrocinadores y asociaciones. Además de las funciones habituales de la gestión patrimonial (conservación e investigación), se ha incidido sobremanera en la divulgación y el uso social y turístico del patrimonio local, como la forma de devolver a la sociedad el fruto de esta gestión, para que perciba de un modo

10 En el Catálogo de Bienes y Espacios Protegidos elaborado en 2008 se recogen 93 elementos patrimoniales, incluidos los declarados BIC (11), Bienes de Relevancia Local (67) y Bienes Catalogados (68). Entre todos ellos destacan 59 monumentos, entre los que se encuentran los principales recursos turísticos patrimoniales de la ciudad. En el cuadro que sigue se muestran doce registros BIC, ya que el pecio Bou Ferrer fue declarado después de la redacción del documento mencionado. 


\section{Cuadro 5 \\ BIENES DE INTERÉS CULTURAL DE LA VILA JOIOSA-PATRIMONIO INMUEBLE}

\begin{tabular}{|c|c|}
\hline NOMBRE & CARACTERÍSTICAS \\
\hline Conjunto Histórico Artístico & $\begin{array}{l}\text { Vila cristiana (1300 Carta Puebla) } \\
\text { ss. XVI-XVIII }\end{array}$ \\
\hline $\begin{array}{r}\text { Iglesia Parroquial de Nuestra Señora } \\
\text { de La Asunción }\end{array}$ & $\begin{array}{l}\text { s. XIV, XVI-XVIII Gótico-Renacimiento } \\
\text { Edificio militar-religioso fortificado }\end{array}$ \\
\hline Murallas & s. XVI-Renacimiento. Edificio militar \\
\hline Torre d'Aguiló & s. XVI. Defensivo. Torre vigía \\
\hline Torre de Xauxelles & s. XVI Defensivo. Torre vigía \\
\hline Torre de Dalt & s. XVI Defensivo. Edificio militar \\
\hline Torre de Hércules & S II d.C. Monumento funerario \\
\hline Torre del Xarco & s. XVI Defensivo. Torre vigía \\
\hline Torre La Cruz & s. XVII Edificio militar. Torre defensiva \\
\hline Torre La Torreta & s. XV Edificio militar. Torre defensiva \\
\hline Torre Simeón & s. XVI-XVIII Edificio militar. Torre defensiva \\
\hline Yacimiento Subacuático Bou Ferrer & $\begin{array}{l}\text { Época romana (2500 ánforas de cargamento } \\
\text { principal) }\end{array}$ \\
\hline
\end{tabular}

Fuente: Dirección General del Patrimonio Cultural Valenciano.

comprensible la productividad cultural y turística de la misma. El objetivo de este plan estratégico consiste en la orientación del municipio hacia un turismo cultural de calidad, cuya iniciativa se encuentra en la creación de un eje patrimonial a partir de la dinamización de tres recursos relevantes como el gran complejo termal de Allon ${ }^{11}$, Vilamuseu y el Chalet de Centella ${ }^{12}$, localizados en la calle Colón, la vía principal del ensanche de la ciudad desarrollado en el siglo XIX.

Vilamuseu tiene sus antecedentes en el antiguo Museo Municipal de Arqueología y Etnografía, reconocido en 1996 y localizado, hasta su cierre temporal en 2010, en la Casa de la Cultura. Desde 2003 se sucedían diferentes propuestas para ubicar un museo de la ciudad, que finalmente fructifican en el proyecto Vilamuseu, ubicado en el antiguo colegio Dr. Esquerdo. Como indica Espinosa (2011) no es únicamente un museo, es un proyecto de ciudad que está desarrollando una red museística y monumental destinada a convertirse en un motor de desarrollo cultural y económico, cuyo objetivo principal es crear un

11 En el año 2006 tuvo lugar el descubrimiento de un complejo termal muy bien conservado, que con seguridad fue construido para conmemorar la promoción de la ciudad de Allon a la categoría de municipium. La importancia de este hallazgo radica en que ha supuesto la prueba fundamental para la ubicación de Allon, una de las cuatro entidades con categoría urbana que Estrabón mostró en su cartografía (Ilici, Lucentum, Dianium, Allon). Blog institucional de Vilamuseu. Fecha de último acceso: 21/7/2015. http://www.vilamuseu.es/ blog/?s=termas + de + Allon.

12 Se trata de un edificio emblemático construido en 1930 por el arquitecto Juan Vidal. En la actualidad alberga la oficina de turismo y en un futuro próximo será objeto de musealización. 
producto de turismo cultural innovador y atractivo. Actúa como el centro de una serie de recursos patrimoniales y de un itinerario cultural que une los puntos más significativos y singulares, preparados para la visita turística ${ }^{13}$.

El proceso de activación patrimonial se basa principalmente en el refuerzo y la promoción de la identidad local, la renovación periódica de contenidos de los museos existentes y la orientación al cliente en todas las actividades contempladas (Espinosa et al., 2011). En este sentido, en el año 1998 se creó el Servicio de Visitas Guiadas, dirigidas a todo tipo de público y desarrolladas a partir de la interpretación, animación, teatralización y recreación histórica ${ }^{14}$. Así, tanto en las visitas guiadas como en las actividades desarrolladas en los museos locales, se realizan estudios de público mediante la observación de comportamientos, para identificar los tiempos dedicados a la observación de determinados recursos, con el fin de realizar un mapa de uso del museo o del sitio de interés que permita identificar las debilidades de la exposición o de la actividad. Los responsables de la gestión patrimonial en este municipio consideran el conocimiento del público como una estrategia fundamental para controlar el éxito de los productos culturales y, por tanto, de la competitividad turística.

Por este motivo, la interpretación del patrimonio es la disciplina que impregna todo el proyecto museológico de la ciudad, incluido obviamente el componente museográfico de Vilamuseu. Así, las exposiciones permanentes y temporales y la planificación y gestión de las visitas guiadas, actividades y programas de difusión patrimonial, se basan en este proceso de comunicación estratégica (Morales y Ham, 2008). Además de la interpretación, el proyecto museográfico contempla la accesibilidad en su acepción de diseño universal arquitectónico y museográfico (Sibina, 2014), que convierte a Vilamuseu en un ejemplo de museología para todos, que cuenta con sus antecedentes en el museo inicial ${ }^{15}$.

Se trata de dos situaciones contrapuestas que reflejan dos realidades distintas en cuanto a los procesos de activación patrimonial con fines turísticos. En el primero de ellos, la mirada turística ha seleccionado desde hace décadas a El Castell de Guadalest a pesar de su escasa autenticidad patrimonial, como lugar identificado con la autenticidad de los municipios de interior, aunque su componente patrimonial posee relativa importancia en el contexto histórico de la comarca. En contraposición, el municipio de la Vila Joiosa, tiene un amplio y relevante conjunto patrimonial, que ha permanecido alejado del fenómeno excursionista de Benidorm porque no reflejaba la imagen auténtica de la mediterraneidad, salvo el núcleo de las conocidas casas pintadas (lienzos de la muralla renacentista del siglo XVI) sobre el cauce del río Amadorio que se han utilizado como imagen promocional

13 Destacan entre ellos, la Casa Museo de la Barbera dels Aragonés, un palacio rural perteneciente a una de las familias más importantes del municipio que contiene una espléndida colección mueble e inmueble de los ss. XVII-XIX; el Museo Valenciano del Chocolate; la Torre de Hércules y la iglesia fortaleza de Nuestra Señora de la Asunción, en el centro histórico. En el año 2013 el Museo Valenciano del Chocolate registró 82.000 visitantes.

14 En este sentido, el caso de la Vila fue pionero. Destacan las visitas teatralizadas Los sueños de Cayetana, desarrolladas en la Casa Museo Barbera dels Aragonés o Una de piratas, dirigida al público infantil, y desarrollada en el centro histórico.

15 En cuestiones de accesibilidad, entre otras muchas acciones, cabe destacar la inauguración de la tercera campaña de visitas guiadas al pecio Bou Ferrer en junio de 2015. En años anteriores, se han realizado visitas de buceo adaptado para personas con discapacidad funcional. Fecha de último acceso: 21/7/2015. http://www.vilamuseu.es/blog/2015/06/inauguracion-de-la-iii-campana-de-visitas-guiadas-al-pecio-bou-ferrer/. Se recomienda la lectura de Juan, Cibecchini y Vento (2011). 
durante años. En cuanto a la gestión del patrimonio local, se observa que los procesos de activación corresponden a concepciones distintas. Mientras que en el primer caso el crecimiento y la mejora de la oferta turística «patrimonial» se realiza conforme adquiere protagonismo la actividad turística, en el caso de la Vila Joiosa, existe un plan museológico de ciudad, en el que se engloban todas las actuaciones de valorización y difusión patrimonial, donde la presencia y la opinión de la población local ha sido uno de los factores que están asegurando el éxito de este proceso de activación patrimonial. En este sentido, el objetivo último consiste en la creación de un producto turístico cultural de calidad en el marco de la concepción del patrimonio cultural como un motor de desarrollo territorial, donde no importa tanto el número de visitantes como la experiencia patrimonial que se realice. En el caso de que los procesos de activación patrimonial con fines turísticos traspasasen el ámbito local, y atendiendo a la selección temática patrimonial existente en el destino de la Costa Blanca, la Vila Joiosa se situaría en una posición competitiva dado que en este municipio se concentran diversas posibilidades de desarrollo de productos turísticos temáticos específicos, como son el arqueoturismo; el turismo industrial a través de la valorización de la actividad chocolatera, y el turismo en centros históricos singulares, todo ello apoyado en una oferta museística de calidad, accesible e interpretativa.

\section{CONCLUSIONES}

Las acciones de recuperación del patrimonio cultural como estrategia de cambio de los destinos turísticos consolidados vienen desarrollándose en el caso español desde finales del pasado siglo XX. Se trata de una estrategia orientada a la cualificación de la experiencia recreativa, la recuperación de la identidad local y la mejora de la imagen del destino. Estas acciones de recuperación y rehabilitación patrimonial con fines turísticos permiten la puesta en valor e integración de nuevos recursos que han permanecido insuficientemente aprovechados, pues el turismo les dota de un valor social y económico añadido de manera que puede contribuir a la preservación ambiental y patrimonial y colabora, por tanto, en el incremento de la calidad ambiental de las localidades afectadas. Por otra parte, estas acciones pueden generar importantes sinergias territoriales entre los espacios litorales y de interior mediante la difusión de los efectos positivos del turismo hacia áreas del traspaís dada la diversidad y preservación de los recursos patrimoniales que albergan esos entornos. Asimismo, el aprovechamiento de estos recursos no debe limitarse a la actividad turística: su puesta en valor por la introducción del turismo permite incorporar y mantener nuevas actividades y usos alternativos basados en el ocio de proximidad, la educación ambiental o las visitas culturales y pueden inducir efectos multiplicadores sobre otras actividades locales y regionales como el transporte, la contratación guías, la restauración o el comercio.

Las excursiones turísticas operadas desde los municipios turísticos del litoral se han convertido, desde los inicios del turismo de masas, en uno de los mecanismos que han vehiculado esas relaciones entre los destinos litorales y las áreas de interior.

A partir del estudio empírico realizado, se ha puesto de manifiesto que la localización de variados recursos en los municipios del traspaís, que inicialmente no cuentan con potencialidad suficiente para generar desarrollos turísticos locales, constituye el factor original 
que ha justificado la creación de esta oferta complementaria al sol y playa. En segundo lugar, accesibilidad y disponibilidad de una masa crítica de servicios se han identificado como elementos claves para entender la ampliación del mapa excursionista y la inclusión en este de distinto municipios y recursos.

No obstante, la eficacia de estos productos como vía de renovación de los destinos consolidados es cuestionable. Es notable la limitada renovación en el catálogo de excursiones, circunscritas espacialmente desde hace años, prácticamente, a los mismos circuitos y lugares. Asimismo, es escasa la innovación en cuanto a los recursos, la tipología de los mismos así como en las técnicas y herramientas de interpretación y difusión cultural utilizadas. En definitiva, se continúan reproduciendo los mismos esquemas y mecanismos que estuvieron en la base de la creación de estas ofertas complementarias.

Los espacios receptores de este excursionismo, especialmente en las áreas del interior, se benefician de la creación de productos recreativos en torno a los recursos principales que generan los flujos así como de limitadas dinámicas comerciales, activadas en los momentos de mayor afluencia de visitantes. Existen, sin embargo, limitaciones y problemas que dificultan la optimización de esas visitas y que pueden llegar a suponer amenazas para las estructuras receptivas:

- alta presión por frecuentación a la que se ven sometidos algunos recursos, lo que puede generar problemas de degradación y banalización, incluso de cierta musealización como ocurre en el caso de algunos centros históricos

- la excesiva especialización funcional y dependencia económica que puede llegar a producirse en destinos de alta frecuentación excursionista, además de la alta dependencia de un único como foco de demanda.

En última instancia, las excursiones turísticas continúan presentándose como una fórmula adecuada como vía de diferenciación del modelo turístico de sol y playa convencional. Sin embargo, para profundizar en esa vía resulta imprescindible incorporar verdaderos objetivos de desarrollo territorial a escala regional y sub-regional e instrumentos de planificación territorial del turismo. En el caso valenciano, el Plan de Espacios Turísticos de la Comunidad Valenciana definió la línea de actuación en ese sentido, al establecer una delimitación de espacios turísticos, asimilables a verdaderos ámbitos geográficos de planificación a escala subregional e incidiendo en distintas acciones orientadas al afianzamiento de las dinámicas de complementariedad territorial y turística litoral-interior de forma que contribuyan a la diversificación de la oferta de ambas áreas y a la desestacionalización de la actividad turística.

A partir del reconocimiento de esa necesidad, se trataría de desarrollar los órganos de gestión y las herramientas de trabajo adecuadas: creación de mancomunidades u otros entes de escala supracomarcal encargados de esa gestión; estudios de evaluación de potencialidades turísticas, capacidad de carga y flujos turísticos para lo cual es necesario solventar el grave déficit de información, tanto cuantitativa como cualitativa, sobre el fenómeno analizado.

En definitiva, se trata de integrar las actuaciones sectoriales turísticas en la política territorial, de manera que mediante las estrategias de complementariedad pueda avanzarse en el doble objetivo de la sostenibilidad se los destinos turísticos litorales y la equidad territorial. 


\section{BIBLIOGRAFÍA}

ANDRIOTIS, K. (2000): Local community perceptions of tourism as a development tool: the island of Crete. Tesis doctoral, Universidad de Bournemouth.

ANDRIOTIS, K. (2006): «Researching the development gap between the hinterland and the coast. Evidence from the island of Crete», Tourism Management, 27, pp. 629-639.

ANTON, S. (2004): «De los procesos de diversificación y cualificación a los productos turísticos emergentes. Cambios y oportunidades en la dinámica reciente del turismo litoral». En Turismo: los retos de un sector estratégico. Papeles de Economía Española, Fundación de las Cajas de Ahorros, 102, 316-333 pp.

BALLART, J. y TRESSERRAS, J. (2001): Gestión del patrimonio cultural, Ariel Patrimonio, pp. 238.

BAÑOS CASTIÑEIRA, C. (2009): Diversidad y complementariedad de recursos para la planificación territorial de la oferta turística en el litoral survalenciano y su área de influencia. Universidad de Alicante. Tesis doctoral inédita.

BRAMWELL, B. (2004): Mass tourism, diversification and sustainability in Southern Europe's coastal regional, en Coastal mass tourism. Diversification and sustainable development in Southern Europe, Bramwell, B. (Ed.), Channel View Publications, Clevedon, pp. 1-31.

CALLE VAQUERO, M. de la (2002): La ciudad histórica como destino turístico, Ariel Patrimonio, Barcelona, pp. 302.

CÁNOVES, G., VILLARINO, M. y HERRERA, L. (2006): «Políticas públicas, turismo rural y sostenibilidad; difícil equilibrio, Boletín de la Asociación de Geógrafos Españoles, $\mathrm{n}^{\circ}$ 41, pp. 199-217.

CHÍAS SURIOL, J. (2002): «Del recurso a la oferta turístico cultural: catálogo de problemas», I Congreso Internacional del Turismo Cultural, Salamanca, 2002.

DÍEZ SANTO, D. (2012): «Los turismos de interior: un enfoque desde la dimensión de las modalidades turístico-recreativas», Documents d'Anàlisi Geogràfica, vol. 58, $\mathrm{n}^{\circ}$ 3, pp. 373-396.

DONAIRE, J.A. (2008): Turismo cultural. Entre la experiencia y el ritual, Edicions Vitel. la, pp, 301.

DONAIRE, J.A., FRAGUELL, R. y MUNDET, Ll. (1998): «La Costa Brava ante los nuevos retos del turismo», Estudios Turísticos, n 133 , pp. 77-96.

ESPINOSA, A. (2002a): «La accesibilidad física e intelectual de todo tipo de público al patrimonio cultural (I)», Boletín de Interpretación, $\mathrm{n}^{\circ}$ 6, pp. 13-15.

ESPINOSA, A. (2002b): «La accesibilidad física e intelectual de todo tipo de público al patrimonio cultural (II)», Boletín de Interpretación, $\mathrm{n}^{\circ}$ 7, pp. 4-6.

ESPINOSA, A. (2011): «Del museu etnogràfic i històric de la Vila Joiosa a Vilamuseu», en La Vila Joiosa». Arqueologia i Museu. Museos Municipales en el MARQ, MARQ, Alicante, pp. 38-49.

ESPINOSA, A y BONMATÍ, C. (2013): ¿Por qué una museología accesible a inclusiva? (O por qué renunciar a la mitad de sus visitantes), en Manual de accesibilidad e inclusión en museos y lugares del patrimonio cultural y natural, Espinosa, A.; Bonmatí, C. (eds.), Ediciones Trea, pp. 303. 
ESPINOSA, A., RUIZ, D., MARCOS, A., BONMATÍ, C., MARÍ, J., VELÁZQUEZ, M.J. y LLORET, M. (2011): La gestió del patrimoni monumental i museístic a la Vila Joiosa: criteris i línies d'actuació en investigació, conservació i divulgació, en la Vila Joiosa. Arqueologia i Museu. Museos Municipales en el MARQ, MARQ, Alicante, pp. 10-37.

FERNÁNDEZ TABALES, A. (2004): «Turismo y ordenación del territorio», Quaderns de Política Econòmica. Revista electrònica. $2^{a}$ época, vol. 7, pp. 35-47.

FERNÁNDEZ TABALES, A. y MENDOZA BONET, A. (2007): La actividad turística en el territorio andaluz: establecimiento de indicadores, distribución y evolución de los mismos, Boletín de la Asociación de Geógrafos Españoles, $\mathrm{n}^{\circ}$ 44, pp. 117-146.

GAVIRIA, M. (1975): El turismo de playa en España: chequeo a 16 ciudades nuevas del ocio, Turner, pp. 329.

GRANDE IBARRA, J. (2001): «Análisis de la oferta de turismo cultural en España», Estudios Turísticos, $\mathrm{n}^{\circ} 150$, pp. 14-40.

GREFFE, X. (2005): «El empleo y los profesionales del patrimonio en Europa», PH: Boletín del Instituto Andaluz del Patrimonio Histórico, Especial Monográfico: patrimonio y empleo, $\mathrm{n}^{\circ} 54$, pp. 87-95.

IDIKUT, A.C. y EDELMAN, D.J. (2003): «Promoting sustainable tourism in coastal cities and their hinterland: the case of Turkey's Bodrum Peninsula», CMU Journal, vol. 2, $\mathrm{n}^{\circ} 2$, pp. 125-136.

IRIBAS, J.M. (2000): Costa ibérica. Hacia la ciudad del ocio. MVRDV Arquitectos, Barcelona, pp. 312.

JORDAN, P. (2000): Restructuring Croatia's coastal resorts: change, sustainable development and the incorporation of rural hinterlands, Journal of Sustainable Tourism, vol $8, n^{\circ} 6$, pp. 525-539.

JUAN de, C., CIBECCHINI, F. y VENTO, E. (2011): «El pecio romano de Bou Ferrer, un velero de comercio naufragado en la costa de la Vila Joiosa», en La Vila Joiosa. Arqueologia i Museu. Museos Municipales en el MARQ, MARQ, Alicante, pp. 178-198.

KOZAK, M; MARTIN, D. (2012): «Tourism life cycle and sustainability analysis: profitfocused strategies for mature destinations», Tourism Management, vol. 33, pp. 188194.

LENO CERRO, F. (1993): Técnicas de evaluación del potencial turístico, Ministerio de Industria, Comercio y Turismo, Secretaría General de Turismo, Madrid, pp. 261.

LÓPEZ PALOMEQUE, F. (Dir.) (2009): Atles del turisme a Catalunya. Barcelona. Generalitat de Catalunya.

LÓPEZ PALOMEQUE, F. y VERA REBOLLO, J.F. (2001): «Espacios y destinos turísticos», en Geografía de España, Gil Olcina, A.; Gómez Mendoza, J. (coords.), Ariel, pp. 545-571.

LÓPEZ, Y. y PULIDO, J.I. (2013): «Productos de turismo cultural», en Turismo cultural, Pulido Hernández, J. I. (Coord.); Calle Vaquero, M. de la; Velasco González, M. Ed. Síntesis, Madrid, pp. 171-202.

MARTÍN, M. (2014): «Por un año nuevo con reflexión... desde la comunicación del patrimonio», Boletín de Interpretación, $\mathrm{n}^{\circ} 29$, pp. 12-14.

MORALES, J. y HAM, S. (2008): «¿A qué interpretación nos referimos?», Boletín de Interpretación, $\mathrm{n}^{\circ}$ 19, pp. 4-7, Asociación para la Interpretación del Patrimonio. 
MUÑOZ MAZON, A.I., FUENTES MORALEDA, L. y FAYOS-SOLÀ, E. (2012): «Turismo como instrumento de desarrollo: una visión alternativa desde factores humanos, sociales e institucionales», Pasos. Revista de Turismo y Patrimonio Cultural, Vol. $10, \mathrm{n}^{\circ} 5$, pp. 437-449.

PRATS, Ll. (2006): «La mercantilización del patrimonio: entre la economía turística y las representaciones identitarias», Boletín del Instituto Andaluz del Patrimonio Histórico, $\mathrm{n}^{\mathrm{o}} 58, \mathrm{pp} .72-80$.

PRATS, Ll (2011): «La viabilidad turística del patrimonio», Pasos. Revista de Turismo y Patrimonio Cultural, Vol. 9, n 2, pp. 249-264.

QUEROL FERNÁNDEZ, M.A. (2010): Manual de gestión del patrimonio cultural, Editorial Akal, pp. 541

RICO CÁNOVAS, E. (2014): El patrimonio cultural como argumento para la renovación de destinos turísticos consolidados del litoral en la provincia de Alicante. Tesis doctoral. Disponible en: http://hdl.handle.net/10045/40780

RICO CÁNOVAS, E. y NAVALÓN GARCÍA, R. (2011): «Accesibilidad y uso turístico del patrimonio cultural en la Costa Blanca: la ruta de los castillos del Vinalopó», en LÓPEZ OLIVARES, D. (Ed.): Renovación de destinos turísticos consolidados. Actas del XIII Congreso Internacional de Turismo, Universidad y Empresa, Valencia, Tirant lo Blanch, pp. 743-761.

RUIZ BAUDRIHAYE, J. (1997): «El turismo cultural: luces y sombras», Estudios Turísticos, $\mathrm{n}^{\circ} 134$, pp. 43-54.

SIBINA, J. (2014): «La museografía de la felicidad. Una museografía accesible para todos», museos.es, 9-10, Ministerio de Educación, Cultura y Deporte. Fecha de último acceso; $21 / 7 / 2015$.

https://sede.educacion.gob.es/publiventa/detalle.action?cod=20155C

SOARES, J. (2012): La evolución de los destinos turísticos litorales consolidados. Un análisis comparado de Balneario Camboriú (Brasil) y Benidorm (España). Tesis doctoral. Disponible en: http://hdl.handle.net/10045/26203

SPILANIS, I. y VAYANNI, H. (2004): «Sustainable tourism: utopia or necessity? The role of new forms of tourism in the Aegean Islands», en Coastal mass tourism. Diversification and sustainable development in Southern Europe, Branwell, B. (Ed.), Channel View Publications, pp. 269-291.

STOCK, M. (2003): Le turisme. Acteurs, lieux et enjeux. Belin. Paris, pp. 299.

TRESSERRAS, J. y MATAMALA, J.C. (2005): «El turismo cultural en España como fuente de empleo para los profesionales del patrimonio», PH: Boletín del Instituto Andaluz del Patrimonio Histórico, Especial Monográfico: patrimonio y empleo, $\mathrm{n}^{\circ}$ 54, pp. 73-83.

VERA REBOLLO, J.F. y BAÑOS CASTIÑEIRA, C.J. (2010): «Renovación y reestructuración de los destinos turísticos consolidados del litoral: las prácticas recreativas en la evolución del espacio turístico», Boletín de la Asociación de Geógrafos Españoles, $\mathrm{n}^{\circ} 53$, pp. 329-353.

VERA, J. F.; LÓPEZ PALOMEQUE, F.; MARCHENA, M.; ANTON, S. (2011): Análisis territorial del turismo y planificación de destinos turísticos. Tirant Lo Blanch, Valencia, pp. 473. 